\title{
An unusual Neisseria isolated from a case of meningitis
}

\author{
P. W. KIPPAX, N. SAEED, AND W. A. V. PAMPLIN \\ From the Department of Pathology, St. James' Hospital, Balham, London
}

SYNOPSIS A Neisseria was isolated from blood culture and cerebrospinal fluid of a child with clinical meningitis. On first isolation this organism failed to produce acid in the usual carbohydrates, and was heavily capsulated. After mouse passage it developed many of the characters of $\underset{\sim}{\sim}$ $N$. meningitidis group $\mathrm{C}$, but was still able to grow at room temperature. Its nature is discussed.

There are scattered but persistent reports in the literature of meningitis due to Neisseria spp. other than Neisseria meningitidis. For example, Branham (1930) reported an outbreak due to an organism which she called $N$. flavescens; Newing and Christie (1947) reported isolation of $N$. catarrhalis from the cerebrospinal fluid of a case of meningitis; Christie and Cook (1947) reported a fatal case due to a capsulated Neisseria and reviewed the literature before that date, whilst Courtois, Thys, and Verselder (1954) reported two cases due to an organism which they called $N$. capsulata.

\section{CASE REPORT}

A 4-year-old coloured child who had come to Britain three years previously was admitted with a history that he was well until $2.30 \mathrm{pm}$ on the day of admission, when he started to cry and complained of pain in the left arm and leg. At $6.30 \mathrm{pm}$ he vomited profusely and started to twitch and jerk. He had been anorexic the whole day and was very feverish. There was no history of recent illness in other members of the family.

On examination, axillary temperature was $101.6 \mathrm{~F}$ and pulse rate 160 per min. He was sleepy but could talk and answer questions. There was a pinkish rash on the body, particularly the chest. The tonsillar lymph nodes were enlarged, and the tonsils themselves enlarged and infected. There was marked neck stiffness and a positive Kernig's sign. The pupils were equal. The fundi were not seen. The right plantar reflex was extensor, the left flexor.

Lumbar puncture showed a cerebrospinal fluid pressure of $130 \mathrm{~mm}$. Protein was $30 \mathrm{mg}$ per $100 \mathrm{ml}$, sugar $77 \mathrm{mg}$ per $100 \mathrm{ml}$, total WBCs 106 per cu mm (differential not reported), total $R B C 45$ per cu $\mathrm{mm}$.

Crystalline penicillin, 10,000 units, was given intrathecally, and this was followed by $125 \mathrm{mg}$ penicillin $\mathrm{V}$, six hourly for six days.

Received for publication 22 November 1967.
Culture of cerebrospinal fluid on blood agar at $37^{\circ} \mathrm{C}$ 을 in $\mathrm{CO}_{2}$ (candle jar) showed a scanty pure growth of aNeisseria colonially resembling $N$. meningitidis, and $\mathrm{a} \subseteq$ blood culture taken at the same time yielded an organism $₹$ which was apparently the same. Both organisms were $\vec{\varphi}$ sensitive to penicillin, ampicillin, chloramphenicol, streptomycin, and erythromycin.

The day after admission his temperature had fallen to normal, although there was still marked neck stiffness, 主 and a second lumbar puncture showed a cerebrospinal fluid pressure of $250 \mathrm{~mm}$. Protein was now $100 \mathrm{mg}$ per $100 \mathrm{ml}$ and there were 6 polymorphs, 10 lymphocytes, $\frac{\AA}{\mathbb{D}}$ and 4 RBCs per cu mm. Clinical improvement was maintained, and he was discharged 10 days after admission.

STAGE 1 BACTERIOLOGICAL INVESTIGATIONS The organisms isolated from cerebrospinal fluid and blood both had the following characteristics when first examined. (We shall refer to these cultures as phase 1 for convenience 3 in description.) They were oval or spherical Gramnegative diplococci of Neisseria type and were heavily $O$ capsulated. After 24 hours at $37^{\circ} \mathrm{C}$ on horse blood agar $₹$ the colonies resembled those of classical $N$. meningitidis. 음 After 12 hours' further incubation at $37^{\circ} \mathrm{C}$, the colonies became rough and the organisms autolysed. Growth did not appear to be influenced by $\mathrm{CO}_{2}$. Subculture on a nutrient (Hartley's broth solidified by adding agar) agar $\mathrm{N}$ slope at room temperature showed some growth after $N$ 24 hours. There was no change in glucose, saccharose, or 0 maltose (serum agar slopes at $37^{\circ} \mathrm{C}$ ). The isolates were $\omega$ oxidase and catalase positive. A saline suspension? killed by heating at $60^{\circ} \mathrm{C}$ for one hour was not 0 agglutinated by polyvalent meningococcus antiserum.

STAGE 2 BACTERIOLOGICAL INVESTIGATIONS Of heavy ${ }^{\top}$ suspensions in saline from overnight cultures on blood agar at $37^{\circ} \mathrm{C}, 0.5 \mathrm{ml}$ aliquots were inoculated intra- $\bigcirc$ peritoneally into two white mice, one receiving the $\overrightarrow{\mathbb{D}}$ culture from cerebrospinal fluid, the other from blood. The mice were sacrificed 18 hours later and the organisms 
were recovered from heart blood and peritoneal cavities of both mice.

These cultures, on blood agar at $37^{\circ} \mathrm{C}$, are referred to as phase 2 , and were retested with the following results. Morphology was as phase 1, but capsules were less evident. Cultures on horse blood agar at $37^{\circ} \mathrm{C}$ were similar to those in phase 1, and growth still occurred on nutrient agar at room temperature. However, the organisms now produced acid from glucose and maltose on serum agar slopes at $37^{\circ} \mathrm{C}$. They were saccharose negative, but oxidase and catalase positive. Live and heat-killed suspension (one hour at $60^{\circ} \mathrm{C}$ ) were now both agglutinated on slides by polyvalent meningococcus antiserum.

FURTHer Serological investigations. Phase 2 organisms were tested by slide agglutination against groups $\mathbf{A}$, $\mathrm{B}, \mathrm{C}$, and $\mathrm{D}$ meningococcus antiserum. Rapid agglutination occurred with anti-C. There was no agglutination with the other three sera. This agglutination ocurred with live organisms and also with saline suspensions, killed by heating at $60^{\circ} \mathrm{C}$ for one hour. (We conclude that the inagglutinability of phase 1 organisms was not due to heating. Live phase 1 organisms were no longer available owing to autolysis of the cultures.)

Group $\mathrm{C}$ meningococcus antiserum (Burroughs Wellcome \& Co. K. 6657) was absorbed for four hours at $37^{\circ} \mathrm{C}$ with equal parts of a heavy suspension of phase 1 organisms heated at $60^{\circ} \mathrm{C}$ for one hour. The supernatant was then tested on slides against phase 2 organisms and against $N$. meningitidis group $\mathrm{C}$ (Wellcome Research Laboratories C.N. 5535). No agglutination occurred. In the same way, phase 2 organisms absorbed agglutinins for the standard group $\mathrm{C}$ meningococcus. The group $\mathrm{C}$ meningococcus antiserum was then absorbed in the same way with $N$. pharyngis (N.C.T.C. 4590). The slide agglutination of our phase 2 and of $N$. meningitidis group $\mathrm{C}$ still occurred.

Since attempts to reproduce these results in tubes were only partly successful, another method was sought.

Seven wells were cut in a sheet of $1 \%$ Oxoid purified agar, with barbiturate buffer of ionic strength 0.025 and $\mathrm{pH} 8$ 8.6. Into the centre well was placed group $\mathrm{C}$ meningococcus antiserum, and into the peripheral wells, in the form of a hexagon, suspensions in $0.25 \%$ phenol saline heated at $60^{\circ} \mathrm{C}$ for one hour, of our phase 2 Neisseria, both from cerebrospinal fluid and from blood culture, of $N$. meningitidis (Wellcome Research Laboratories C.N. 5535), and of $N$. pharyngis (N.C.T.C. 4590). No precipitation lines were seen after diffusion for seven days at refrigerator temperature, but staining with Chromassie blue (Gurr), showed lines suggesting identity between our phase 2 Neisseria and $N$. meningitidis group C.

Attempts to reproduce this experiment met with only partial success. We therefore modified the medium by adding $0.003 \%$ ethylenediamine tetraacetate (Reising and Kellogg, 1965) and carried out diffusion at room temperature for four days. Precipitation lines were now visible without the need for staining, a reaction of identity appearing between our phase 2 Neisseria (from cerebrospinal fluid and blood) and the standard

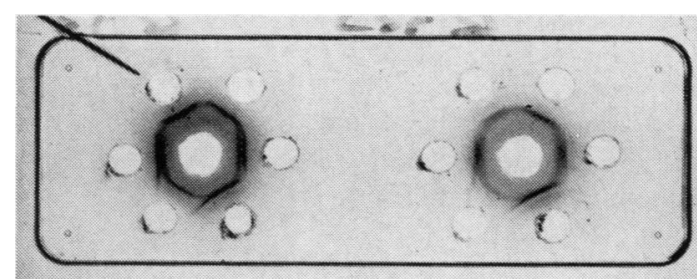

FIG. 1. Agar gel diffusion in duplicate, stained with amidoblack (natural size). The central well contains Meningococcus group $C$ antiserum. The peripheral wells, starting at the pointer (top left) and reading clockwise, contain suspensions of Neisseria from cerebrospinal fuid, Neisseria from blood culture, Meningococcus group $C$, Neisseria from cerebrospinal fluid, Neisseria pharyngis, Meningococcus group $C$.

group C meningococcus. A reaction of partial identity, with a pronounced spur, occurred where our phase 2 Neisseria and the group $C$ meningococcus were placed one on either side of $N$. pharyngis (Fig. 1). Similar results were obtained after four days' diffusion in the refrigerator, but all lines were fainter. Attempts to reproduce these results with the phenol extraction method described by Reisingg and Kellog (1965) have so far failed.

\section{DISCUSSION}

We suggest that this isolate is an atypical strain of $N$. meningitidis group $\mathrm{C}$ for the reason that (1) it was isolated from blood and cerebrospinal fluid of an early case of meningitis which responded rapidly to penicillin. (2) After mouse passage it fermented glucose and maltose, but not saccharose, and was agglutinated on slides by group $\mathrm{C}$ meningococcus antiserum, from which it absorbed agglutinins for a strain of group $\mathrm{C}$ meningococcus. Cultures before passage were also able to absorb these agglutinins. (3) After mouse passage, on immunodiffusion against group $\mathrm{C}$ meningococcus antiserum, a reaction of identity with a standard group $\mathrm{C}$ meningococcus was seen.

Against our suggestion are (1) failure in this case to exclude viral aetiology; (2) ability of the organisms to grow at room temperature (growth on nutrient agar has been reported, eg, Cruickshank, 1965); (3) failure to confirm results of slide agglutination satisfactorily in tubes.

What relationship this isolate bears to $N$. capsulata of Courtois et al. (1954) must be a matter for speculation, but as first isolated it resembles it in being grown from a case of meningitis, in being strongly capsulated and inagglutinable by meningococcus antiserum, in growing at temperatures below $37^{\circ} \mathrm{C}\left(N\right.$. capsulata grew at $\left.28^{\circ} \mathrm{C}\right)$ in failing to produce acid from glucose, saccharose, or maltose 
and in undergoing such rapid autolysis that some of our cultures and those of the Belgian authors were lost.

Inagglutinable strains of $N$. meningitidis have been reported as not infrequent during interepidemic periods (Wilson and Miles, 1964).

Thanks are due to Dr J. H. Burkinshaw for permission to publish the clinical details; to $\operatorname{Dr}$ A. J. H. Thomlinson for advice and encouragement; to Dr E. Kawerau for help with the initial stages of the immunodiffusion experiments; to Dr S. P. Lapage for confirming cultural and biochemical findings on our phase 2 organism and for supplying cultures of $N$. meningitidis group $\mathrm{C}$, $N$. flavescens and $N$. pharyngis; to Mr G. H. Turner,
Biological Division, Wellcome Research Laboratories for supplying the C.N. 5535 group $\mathrm{C}$ meningococcus; to 을 Miss N. Barthen for technical assistance; and to Miss J. M. Hodgkin for the photograph.

\section{REFERENCES}

Branham, S. E. (1930). Publ. Hlth Rep. (Wash.), 45, 845.

Christie, A. L. M., and Cook, G. T. (1947). J. Hyg. (Lond.), 45, 149. Courtois, G., Thys, A., and Verselder, R. (1954). Ann. Soc. belge Méd. trop., 34, 13.

Cruickshank, R. (Editor) (1965). Medical Microbiology, 11th ed CO p. 169. Livingstone, Edinburgh.

Newing, W. J., and Christie, R. (1947). Med. J. Aust., 1, 306.

Reising, G., and Kellogg, D. S., Jr. (1965), Proc. Soc. exp. Biol. (N. Y.), $120,660$.

Wilson, G. S., and Miles, A. A. (Editors). (1964). Topley and Wilson's Principles of Bacteriology and Immunity, 5th ed. vol. 1, p. 669. Arnold, London. 